
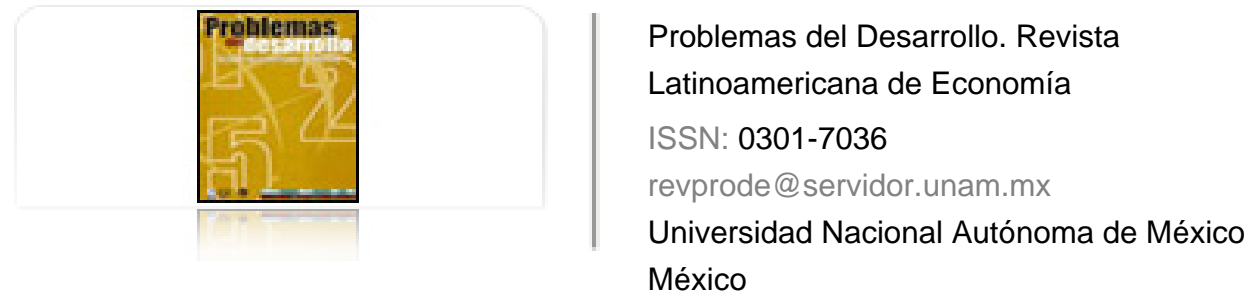

Rapoport, Mario; Brenta, Noemí

La crisis económica mundial: ¿el desenlace de cuarenta años de inestabilidad? Problemas del Desarrollo. Revista Latinoamericana de Economía, vol. 41, núm. 163, octubrediciembre, 2010, pp. 7-30

Universidad Nacional Autónoma de México

Distrito Federal, México

Disponible en: http://www.redalyc.org/articulo.oa?id=11819762002

Cómo citar el artículo

- Número completo

- Más información del artículo

Página de la revista en redalyc.org

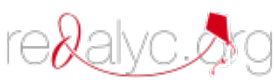

Sistema de Información Científica

Red de Revistas Científicas de América Latina, el Caribe, España y Portugal Proyecto académico sin fines de lucro, desarrollado bajo la iniciativa de acceso abierto 
Revista Problemas del Desarrollo, 163 (41), octubre-diciembre 2010

\title{
LA CRISIS ECONÓMICA MUNDIAL: ¿EL DESENLACE DE CUARENTA AÑOS DE INESTABILIDAD?
}

\author{
Mario Rapoport* y Noemí Brenta**
}

Fecha de recepción: 23 de junio de 2010. Fecha de aceptación: 26 de septiembre de 2010.

\section{RESUMEN}

Las crisis económicas mundiales expresan las tensiones del régimen de acumulación imposibles de resolver según el funcionamiento ordinario del sistema. A la gran crisis de 1929 siguió una depresión superada definitivamente al enorme costo de la II Guerra Mundial. Luego de la expansión de posguerra, la crisis de los años setenta marcó una inflexión. Desde entonces sucesivas crisis se repitieron periódicamente en las cuatro décadas siguientes, con lapsos cortos de recuperación, hasta el estallido de 2007. Este trabajo revisa la crisis actual a la luz de esos 40 años, analiza los ciclos coyunturales y los condicionantes estructurales, los cambios en el pensamiento económico y los intereses en juego, las regularidades y las divergencias entre las crisis desde 1929, las principales fuerzas en pugna y las tendencias futuras que ya se avizoran.

\section{PALABRAS CLAVE}

Crisis, ciclos económicos, crisis financieras, euro, dólar, China.

\footnotetext{
* Director del Instituto de Estudios Históricos, Económicos, Sociales e Internacionales (IDEHESI)-Consejo Nacional de Investigaciones Científicas y Técnicas de la Argentina y Universidad de Buenos Aires. Investigador Superior del Conicet. Profesor Titular Consulto de la UBA. Correo electrónico: irapopor@econ.uba.ar

** Investigadora y coordinadora académica del IDEHESI. Profesora de la UBA. Correo electrónico: nbrenta@fibertel.com.ar
} 


\title{
Abstract
}

World economic crises express the tensions of a system of accumulation impossible to resolve through the normal functioning of the system. The crash of 1929 was followed by a depression definitively overcome through the enormous cost of the Second World War. Following the post-war expansion, the crisis of the 1970s registered an inflection point. From then on successive crises were repeated periodically for the next four decades, with short lapses of recovery, until the outbreak of 2007. This paper reviews the present crisis in the light of those 40 years, analyzing the relevant cycles and structural conditioning, the changes in economic thinking and interests at play, the regularities and divergences of the crises since 1929, the main forces in conflict and the future trends now being fuelled.

Key words: crises, economic cycles, financial crises, euro, dollar, China,

\section{Résumé}

Les crises économiques mondiales expriment les tensions du régime d'accumulation impossibles à résoudre dans les conditions ordinaires de fonctionnement du système. A la grande crise de 1929 a fait suite une dépression surmontée définitivement au prix de la seconde guerre mondiale. Après l'expansion de l'après-guerre, la crise des années 70 a marqué une inflexion. Depuis lors des crises successives se sont répétées périodiquement au cours des quatre décennies suivantes, avec de courtes périodes de récupération, jusqu’à celle qui a éclaté en 2007. Ce travail passe en revue la crise actuelle sous l'éclairage de ces 40 années, analyse les cycles conjoncturels et les facteurs structurels, les changements survenus dans la pensée économique et dans les intérêts en jeu, les analogies et les divergences entre les crises depuis 1929, les principales forces qui s'affrontent et les tendances futures qui se font déjà jour.

Mots clés : crises, cycles économiques, crise financière, euro, dollar, Chine.

\section{Resumo}

As crises econômicas mundiais expressam as tensōes do regime de acumulação impossíveis de se resolver segundo o funcionamento normal do sistema. Depois da grande crise de 1929, se assistiu a uma depressáo que foi superada definitivamente a partir do enorme custo da II Guerra Mundial. Após o boom do pós-guerra, a crise da década de 70 marcou um ponto de inflexão. Desde entấo sucessivas crises se repetiram periodicamente nas próximas quatro décadas, com lapsos mais curtos de recuperaçáo, até o início de 2007. Este artigo reexamina a crise atual à luz destes 40 anos, analisa os ciclos conjunturais e os condicionantes estruturais, as mudanças no pensamento econômico e os interesses em jogo, as regularidades e as diferenças entre as crises desde 1929, as principais forças em disputa e as tendências futuras, que já podem ser vislumbradas.

Palavras-chave: crise, ciclos econômicos, crise financeira, euro, dólar, China.

\author{
世界经济危机：四十年不稳定的结果吗？ \\ 综述 \\ 全球经济危机诠释了正常体系运作不能解决的长期积攒的制度的内部矛盾问 \\ 题。1929年危机之后的经济萧条, 是比第二次世界大战还要惨重的代价. 战后 \\ 的扩张, 70年代危机标志着一个转折点。自那时以来在未来四十年中历次危机 \\ 复发定期（历次定期复发），其恢复时期缩短了，直到2007年爆发的金融危 \\ 机。本文综述了在这40年中光目前的危机, 分析了经济周期和结构状况, 经济 \\ 思想的变化和各种利益冲突, 1929年以来各经济危机之间的存在的规律性和 \\ 差别, 不同派别的斗争以及已经可以看到未来的趋势。 \\ 关键词：危机，经济周期，金融危机，欧元，美元，中国，
}




\section{EL CONCEPTO DE CRISIS Y EL PAPEL DE LAS CRISIS FINANCIERAS EN EL CAPITALISMO}

El término crisis referencia en una economía de mercado a la cuestión de los ciclos o fluctuaciones económicas. No son factores externos al sistema, como los desastres climáticos o las guerras, los que originan las crisis, aunque pueden coadyuvar a ellas, sino elementos endógenos al mismo. En particular, lo que caracteriza el periodo de contracción o recesión, cuya fase más aguda llamamos crisis, es la disminución general de la actividad económica, reflejada en la baja de la producción de bienes y servicios y del empleo, acompañada por una reducción general del nivel de beneficios, precios y salarios.

Técnicamente la crisis se define como el punto de inflexión de un ciclo, el momento en que de la prosperidad se pasa a la recesión. Pero este fenómeno también implica una perturbación dramática de la vida de una sociedad. La idea de crisis - dice el filósofo Edgard Morin- "está conformada por una constelación de nociones interrelacionadas: la idea de perturbación [...], la de progresión de las incertidumbres; la de parálisis y rigidez de aquello que constituía la flexibilidad organizativa del sistema, de los dispositivos de respuesta y regulación". Con la incertidumbre -añade Morin- "el hombre actual ha perdido la promesa de un progreso predicho infaliblemente por las leyes deterministas de la historia o del desarrollo lógico de la ciencia y de la razón” (Figallo y Ceretto, 2003: 23).

Las crisis del capitalismo contemporáneo más importantes fueron la de 1929, la de los años 1970 y la actual, estas dos últimas vinculadas en el tiempo y de las que nos ocuparemos más específicamente. Por cierto, las fluctuaciones en los mercados financieros juegan un rol propio, y a menudo fundamental (como en 1929 y sobre todo en la crisis actual), en los periodos de expansión (burbuja especulativa) y contracción posterior. Las crisis financieras pueden anticiparse a una caída de la economía real, acompañarla o ser un resultado de ella, pero nunca constituyen una manifestación aislada; forman parte de procesos más profundos, de corto o largo plazo, de carácter ocasional o sistémico. La separación entre las finanzas y la economía real en las últimas cuatro décadas y la primacía creciente de aquéllas, llevaron el foco histórico y teórico del tema sobre el comportamiento de los mercados financieros. ${ }^{1}$

Ya Marx y Keynes alertaban, desde sus distintas visiones, acerca de la posibilidad de una disociación entre los sectores productivos y ese tipo de mercados, capaz de generar situaciones desestabilizadoras del sistema. Para Marx, "las crisis son siempre soluciones violentas puramente momentáneas de las contradicciones existentes [...]”. Una de ellas "consiste en que el modo capitalista de producción tiende al desarrollo absoluto de las fuerzas productivas, con prescindencia del valor y del plusvalor encerrado en él [...]; mientras que, por otra parte, tiene como finalidad la conservación del valor de capital

1 Una introducción necesaria es el libro de Kindleberger, 1991 [1989]. Ver más recientemente las obras de Marichal, 2010 y Stiglitz, 2010. 
existente y su valorización en medida extrema. Los métodos por medio de los cuales logra esto incluyen la disminución de la cuota de ganancia”. Éste es el corazón de la interpretación marxista de la crisis, la caída de la tasa de ganancia, uno de cuyos factores es la valorización excesiva del capital. $^{2}$

Según Keynes, los valores financieros constituyen, ante todo, un intento de los productores de reducir los riesgos asociados con la inversión en la producción, siendo también más fácilmente transferibles. Coexisten, entonces, en el capitalismo, dos estructuras de precios diferentes: los de la producción física y los de los activos financieros, que operan separadamente. Si los activos de largo plazo de las corporaciones se convierten en títulos de corto plazo para los inversores, la economía será cada vez más prisionera de la especulación sobre esos valores generando una alta volatilidad e inestabilidad (Foster y Magdoff, 2009: 16).

Siguiendo este razonamiento, la explicación más completa de las crisis en los mercados financieros se debe a Hyman Minsky, cuya reputación, como señala Kindleberger "es la de ser especialmente pesimista, incluso lúgubre, por su énfasis en la fragilidad del sistema financiero y su propensión al desastre” (Kindleberger, 1991 [1989]: 34-52). Una fragilidad que Minsky considera inevitable allí donde reina la libertad de mercado, razón por la cual considera que el sistema financiero debe ser regulado por los bancos centrales o los gobiernos.

Minsky otorga particular importancia a las estructuras de las deudas como causantes de las crisis y, en particular, a las deudas contraídas para adquirir activos financieros a fin de revenderlos. Pero su hipótesis central es que la inestabilidad de esos mercados es endógena; en otros términos, una "inestabilidad inherente" al comportamiento de los actores financieros y de las empresas. En sus propias palabras "la inestabilidad es determinada por mecanismos dentro del sistema y no fuera de él; nuestra economía no es inestable porque está impactada por [los precios del] petróleo, guerras o sorpresivos cambios monetarios, sino por su [misma] naturaleza" (Minsky, 2008 [1986]: 192). A los dos grandes problemas del capitalismo, el desempleo y la desigualdad en la distribución de los ingresos, Minsky agrega un tercero: la persistente inestabilidad del régimen dominado por las finanzas.

Avanzando por este sendero teórico, Harry Magdoff y Paul Sweezy hallaron que el estancamiento de la inversión está estrechamente interrelacionado con la financiarización de la economía. En verdad, las finanzas especulativas constituyen una usina secundaria de crecimiento dada la caída de las tasas de rentabilidad y la debilidad de la inversión productiva; pero al mismo tiempo aceleran el proceso de endeudamiento. El interés del capital monopolista en hacer rentables sus plusvalores ante la falta de oportunidades de inversión que garanticen tal cosa en la economía real, crea las burbujas especulativas: "la economía no puede vivir sin financiarización [...] y no puede al final vivir

2 Marx, 2006 [1897], p. 320. Hilferding, 1963 [1910], uno de sus discípulos, desarrolla extensamente esta idea. 
con ella" (Foster y Magdoff, 2009: 18-19). ${ }^{3}$ Esta fuerza que procura contrabalancear el estancamiento, se convierte en un boomerang y desencadena la crisis.

Por otro lado, como señalan John Eatwell y Lance Taylor, "la escala y los flujos financieros en el nuevo orden financiero internacional [...] destruyeron las fronteras existentes entre los mercados de capital nacionales y el mercado financiero internacional"; un proceso que se vio facilitado por la aplicación generalizada de la informática y el salto en la tecnología de las comunicaciones (Eatwell y Lance Taylor, 2005: 20).

El predominio del sector financiero sobre la economía real se expresó en las políticas económicas de los países desarrollados con el retorno a tasas de interés fuertemente positivas para reducir la inflación y atraer capitales. Pero el proceso de globalización financiera implicó, sobre todo, un cambio significativo en las reglas de juego. Permitió a los agentes económicos tomar o colocar su dinero sin límites gracias al conjunto de instrumentos que les ofreció el mercado y facilitó las prácticas especulativas. En poco más de treinta años el sector financiero creció en todos sus indicadores varias veces más que las actividades productivas como lo muestra el siguiente cuadro. ${ }^{4}$

Cuadro 1. Evolución del sector financiero en la economía mundial

\begin{tabular}{lcc}
\hline Concepto & Periodo & Cantidades \\
\hline Crecimiento del stock de activos financieros globales & $1980-2007$ & 9 veces \\
Crecimiento del stock de activos financieros globales/producción mundial & $1980-2007$ & 4 veces \\
$\begin{array}{l}\text { Crecimiento de los beneficios de la industria financiera en EE.UU./total de beneficios } \\
\text { corporativos }\end{array}$ & $1980-2007$ & $10 \%$ al 40\% \\
Crecimiento del valor bruto del mercado financiero/producción mundial & $1997-2007$ & 8 veces \\
Crecimiento del número de hedge funds (fondos especulativos) & $1990-2007$ & 610 a 10.000 \\
\hline
\end{tabular}

Fuente: Elaboración propia en base a J. G. Palma (2009); The Economist, 24-1-2009.

\section{LA TEORÍA DE LOS “MERCADOS EFICIENTES” Y SUS FALACIAS}

La hipótesis de los mercados eficientes sostiene que los precios de mercado llegan a ser, sobre la base de la información disponible, las mejores estimaciones de sus valores reales. Este supuesto jugó un papel fundamental en la crisis mundial de 2007-2010.5 El modelo de Harry Markowitz, lanzado en su tesis doctoral en la Universidad de Chicago

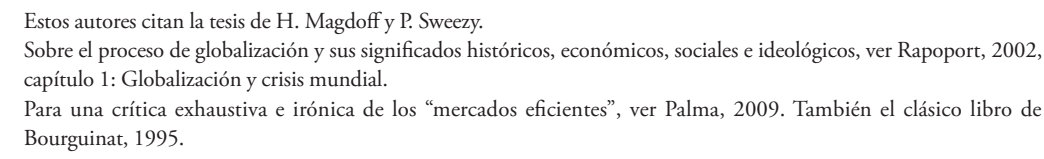


en 1952, procura orientar la selección de los portafolios de inversión. Asumiendo el comportamiento racional del inversor, el riesgo de un activo financiero se calcula midiendo la varianza histórica de su rentabilidad. Por lo tanto, el inversor puede reducir el riesgo de su cartera eligiendo activos cuyas oscilaciones no se correlacionen, y maximizar su rendimiento para un nivel de riesgo dado. Los mercados financieros brindan así a cada ahorrista la posibilidad de elegir "científicamente" sus inversiones. Hay que optar entre un determinado rendimiento y la ausencia de riesgo, pero el mercado es siempre eficiente. ${ }^{6}$ Luego, otros economistas comenzaron a analizar los mercados financieros suponiendo que los inversores se comportaban tal como lo había predicho Markowitz (posteriormente nobelizado). Una verdadera tautología.

Esta línea de pensamiento, pero con el objetivo puesto en obtener rentabilidades más altas y seguras, llevó a un desastre mayor con otros dos premios Nobel, Robert Merton y Myron Scholes, quienes crearon un modelo matemático para valuar las opciones (contratos que confieren a los inversores el derecho a comprar o vender activos a precios predeterminados). Los operadores financieros utilizaron esta fórmula -que fundamentó el desarrollo de los productos derivados, uno de los mercados más especulativos- desde los años setenta para cubrirse contra las fluctuaciones de las cotizaciones de títulos y productos, sobre todo después del primer shock petrolero (La Documentation Française, 1999: 34). Sobre esa base Merton y Scholes integraron el consejo de administración de un fondo especulativo, el Long Term Capital Management, que en 1998 sufrió una de las mayores bancarrotas financieras en la historia de los Estados Unidos. Gary Becker, otro premio Nobel, adscripto a las mismas ideas, confiesa en una entrevista reciente que no imaginaba "que tendríamos semejante crisis financiera". Ni tampoco que esa crisis "podía tener un efecto tan grande en el sector real, en la producción y el desempleo".?

El aforismo de Mark Twain "la previsión es difícil, sobre todo cuando ella se refiere al porvenir", se aplica plenamente tanto a Becker, que admite su fracaso en este sentido, como a las fórmulas de Markowitz y de Merton y Scholes, que se revelaron equivocadas en la práctica misma. André Orléan, completando a Minsky, explica en pocas palabras el carácter erróneo de esas teorías: "Mientras que en los mercados de bienes un aumento o disminución de los precios conlleva a una baja o un alza de la demanda que tiende a estabilizar la situación -dice-, tal cosa no ocurre en los mercados financieros. En éstos, un incremento o una caída de los precios, puede provocar (a la inversa del caso anterior) un alza o una disminución de la demanda, generando una dinámica acumulativa de los precios al alza o a la baja”. De este modo, esos mercados son estructuralmente inestables y originan crisis frecuentes. ${ }^{8}$

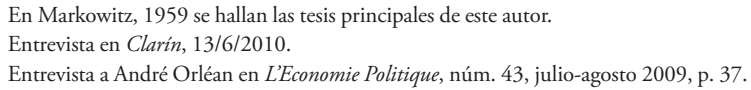




\section{LAS CRISIS EN EL CENTRO Y EN LA PERIFERIA EN LOS ÚLTIMOS CUARENTA AÑOS}

La expansión de posguerra, un periodo sin crisis a nivel regional o global, llegó a su fin en la década del setenta con una nueva situación crítica en la economía mundial. No hubo entonces un crac en la bolsa de valores, como en la crisis de 1929, sino otros hechos decisivos: algunos que reflejaban tendencias históricas, como la caída de las tasas de ganancia; y otros más coyunturales, como el colapso del orden monetario internacional establecido en Bretton Woods y la cuestión del petróleo.?

La rentabilidad del capital disminuyó en todos los países desarrollados. Particularmente, un 6.4\% entre 1966-1974 en los EE.UU.; un 6,8\% entre 1968-1973 en Alemania y un 8.8\% entre 1970-1975 en Gran Bretaña y Francia (C.E.P.I.I., 1983: 170 y 174-175). A su vez, la crisis del dólar en 1971, y luego la del aumento de los precios del petróleo en 1973 (repetida en 1979), contribuyeron a iniciar una nueva era del capitalismo.

Esa caída de las tasas de ganancia respondió a varios factores: la creciente competencia en el terreno económico y monetario entre Estados Unidos, Europa Occidental y Japón; los enormes costos y el desgaste político y militar de la intervención de Washington en Vietnam, y de la carrera armamentista y espacial; el auge del poder sindical y de los movimientos sociales en el primer y tercer mundo criticando las sociedades de consumo o procurando mayores márgenes de autonomía en lo externo y de equidad en la distribución de los ingresos; y la desaceleración del crecimiento de la productividad en las economías más avanzadas.

La crisis frenó la expansión económica del periodo de posguerra, generando la estanflación (estancamiento con inflación). Para contrarrestarla, las políticas fiscales y monetarias procuraron recortar los beneficios del Estado de Bienestar. Se instaló entonces el triángulo recesión, inflación, desocupación, y el consumo disminuyó. A consecuencia de esto último, y de la crisis monetaria, el sector financiero amplió su presencia y empezó a predominar sobre el sector real donde la acumulación de capital resultó afectada. El crecimiento de los países desarrollados disminuyó sensiblemente aunque se incrementó el de países emergentes (China, India, Sudeste asiático)

$\mathrm{Al}$ mismo tiempo en entidades académicas y empresariales fue creciendo una fuerte corriente de economistas ortodoxos, que aprovecharon la crisis de los años setenta para influir decisivamente sobre el poder político dando fundamento a lo que se dio en llamar neoliberalismo. Los ortodoxos, desde las teorías monetaristas, criticaban la curva de Phillips, ligada al esquema keynesiano que postula la existencia de una relación inversa entre inflación y desempleo, y afirma que una política dirigida a la estabilidad de precios promueve desocupación. Por tanto, cierto nivel de inflación es necesario a

9 Sobre el orden monetario internacional de posguerra ver Brenta, 2008, capítulos 1 al 6. 
fin de mantener el pleno empleo. Friedman, Phelps y sus colegas monetaristas estimaron que la relación de Phillips no se cumple, por lo que una política fiscal, de aumento de la demanda efectiva, no es eficaz para resolver el desempleo. Para ellos, ninguna intervención del Estado en el sentido keynesiano sería practicable debido a la existencia de una tasa natural de desocupación con un cierto nivel de inflación. Resulta entonces prioritario atacar la inflación, abandonando la idea del pleno empleo, con el propósito de restablecer los niveles de rentabilidad e impulsar nuevamente la economía (Friedman, 1968).

El resultado no fue satisfactorio. Desde los años setenta, el mundo comenzó a ser escenario de una serie de crisis sucesivas que afectaron a varias naciones y zonas geográficas, alternadas con etapas más cortas de crecimiento según los países. Es significativo en términos del análisis comparado, que los periodos de auge o recuperación de la economía de Estados Unidos coincidieron por lo general con crisis profundas en la periferia y viceversa.

Raúl Prebisch señala en un artículo publicado en 1921, donde analiza las crisis argentinas de fines del siglo XIX, la existencia de la "coyuntura inversa". Los ciclos económicos internos de la Argentina se vinculaban a los de Gran Bretańa de una manera particular: cuando se acumulaba liquidez en la metrópoli porque caían las tasas de rentabilidad, los capitales se dirigían al país del Cono Sur, que iniciaba una fase ascendente de su ciclo económico. Esa fase duraba hasta que en el centro se manifestaban tendencias recesivas - provocando, por ejemplo, un alza de las tasas de interés-, y los capitales retornaban dejando en la Argentina altos niveles de endeudamiento y crisis económica (Prebisch, 1991: 126, nota al pie 66). Si bien la dinámica centro-periferia estadounidense es bastante diferente de la británica, como señala el mismo Prebisch (Prebisch, 1948: 96-97), -ya que los Estados Unidos se autoabastecen de materias primas mucho más que Gran Bretańa, que era importadora neta de ellas- el comportamiento de los movimientos de capitales siguen prácticamente la misma lógica en ambas hegemonías.

Al comparar la evolución de las economías estadounidense y sudamericana (Brasil, Uruguay, Argentina, Colombia, Chile y Bolivia), entre 1974 y 2008, tomando promedios móviles de cinco años a fin de suavizar las curvas, se comprueba el cumplimiento de los ciclos de coyuntura inversa en términos generales, salvo a partir de 2002-2003 cuando la recuperación sudamericana se financia endógenamente, mientras que la caída estadounidense obedece a un largo proceso de endeudamiento interno y externo que culmina en la crisis de $2007 . .^{10}$

10 Las tasas medias móviles se confeccionaron a partir del promedio aritmético de las tasas de crecimiento del ańo en curso y los cuatro anteriores, lo que permite incorporar al análisis las tendencias históricas. Es sugestivo que aun así, las curvas se cruzan en 1982, 1989 y 1999, reflejando bastante fielmente los puntos de inflexión reales. 
Gráfico 1. Comparación entre los ciclos de EE.UU. y Sudamérica

Tasas medias móviles de variación del PIB

EE.UU. y Sudamérica. 1974-2008

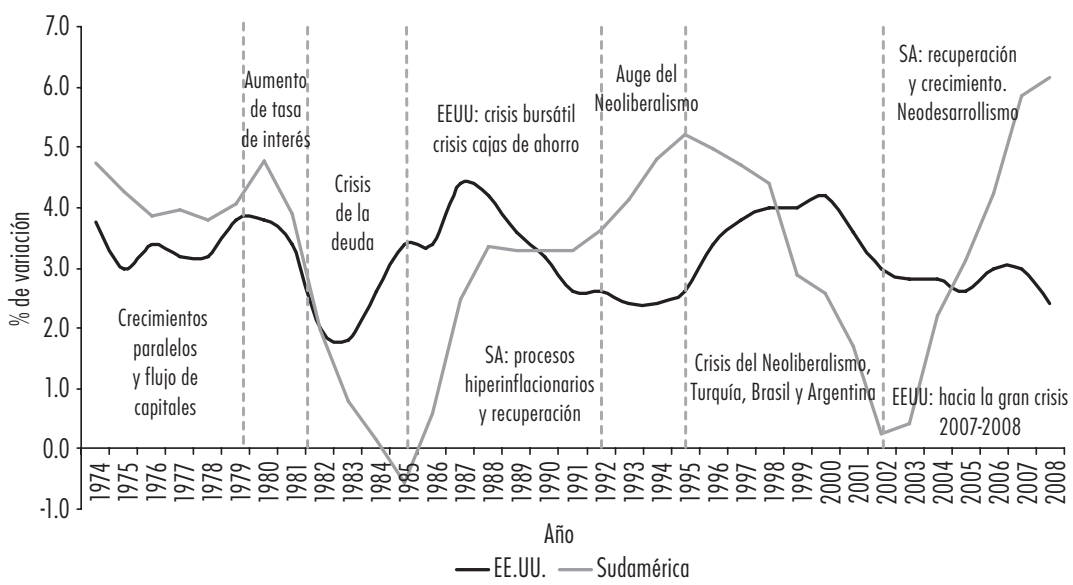

Fuente: Elaboración propia con datos del Banco Mundial y CEPAL

La crisis de la deuda latinoamericana, que se inicia en 1981 y se agudiza en 1982, esta tendencia se acentúa hasta 1985 tomando medias móviles (ver Gráfico 1), se debió en gran medida al alza de las tasas de interés de la Reserva Federal desde 1979, y constituye un ejemplo de las tesis de Prebisch. A su vez, la economía estadounidense empezó a recuperarse en 1983, luego de una fuerte recesión, gracias, entre otras cosas, al retorno acrecentado, vía las mayores tasas de interés, de capitales colocados anteriormente en los países deudores. ${ }^{11}$

Estas políticas impulsaron la recuperación del país del norte, pero otro crac bursátil en Wall Street, en 1987, ocasionó pérdidas tan o más importantes que las de 1929. El derrumbe político y económico de la superpotencia rival y el fin de la Guerra Fría significaron para los Estados Unidos la posibilidad de iniciar una larga etapa de prosperidad. Sin embargo, esto no ocurrió de inmediato porque la crisis de las cajas de ahorro en 1989, volvió a afectar seriamente a la potencia del norte.

11 Lo que se sumaba a la atracción de capitales provenientes de otras partes del mundo y al elevado gasto público de la "revolución conservadora” en el complejo militar-espacial, dirigido a consolidar la supremacía estadounidense sobre la agonizante Unión Soviética. 


\section{Mario Rapoport y Noemí Brenta}

Recién a partir de 1992, con la "nueva economía" del conocimiento, se retomó la senda de crecimiento en el marco de una ola especulativa. Como señala Krugman,

"la burbuja de las acciones de los años noventa reflejaba principalmente dos cosas. Una de ellas ha recibido mucha atención: el optimismo extremo acerca de las ganancias potenciales de la tecnología de la información. La otra, el creciente sentimiento de seguridad acerca de la economía, la creencia de que los días de las recesiones severas habían quedado atrás, no mereció tanta publicidad. Pero actuaron juntas para empujar los precios de las acciones a niveles sorprendentes" (Krugman, 2009: 151).

Este proceso se mantuvo hasta la recesión del 2000, que se tratará en el acápite siguiente,

También en esa década, una nueva corriente de capitales fluyó hacia los países periféricos, entre ellos los latinoamericanos, impulsada por políticas que permitían la libre movilidad de los mismos y las privatizaciones de activos públicos una vez regularizadas las deudas soberanas a través del Plan Brady. Pero este ciclo de endeudamiento fue muy inestable y entró pronto en problemas, aun más rápidamente que el de los setenta. Entre mediados de la década y comienzos del nuevo siglo, México, Turquía, Rusia, Brasil y, finalmente Argentina padecieron sucesivas crisis. También los exitosos "tigres asiáticos" -cuyo formidable avance tecnológico e industrial siguió un camino distinto, con fuerte presencia del Estado- sufrieron un derrumbe económico entre cuyas causas estuvieron presentes políticas de financiarización de sus economías impulsadas por el FMI.

En este periodo las crisis no fueron globales sino geográficas o sectoriales: afectaron a algunas ramas de la producción más que a otras mientras se expandían la informática, el sector financiero y las comunicaciones. A su vez, en ciertas regiones, como en la Unión Europea, las tasas de crecimiento cayeron sensiblemente; mientras en países emergentes, como China, el crecimiento, ya vigoroso, se intensificó entrando al nuevo siglo y en Japón se vivía una larga fase de estancamiento.

Finalmente, la recuperación de la economía norteamericana en 2002-2006 basada en la burbuja de las viviendas, la baja de las tasas de interés, el endeudamiento público y privado y los gastos militares, se detuvo en forma abrupta con la crisis de las subprime en $2007 .{ }^{12}$ Una crisis que se expandió rápidamente en el mundo afectando en particular a Europa.

El Gráfico 2 refleja, según un índice que incluye los valores bursátiles de 23 países desarrollados, momentos clave que marcan tanto las burbujas especulativas como las

12 La era del dinero fácil tuvo que ver con la política de la Reserva Federal y de quien fuera su presidente entre 1987 y 2006, Alan Greenspan, que calificó esas burbujas de "exuberancia irracional" (cf. Greenspan, 2008: 199). Luego reconoció que la idea de la "autorregulación de los mercados" había fracasado en una audiencia en el Congreso de Estados Unidos el 23 de octubre de 2008; y planteó la necesidad de regular las finanzas, en su artículo "The crisis" (disponible en ww.brookings.edu/ //media/Files/Programs/ES/BPEA/2010_spring_bpea_papers/spring2010_greenspan.pdf). 
La crisis económica mundial: ¿̇el desenlace de cuarenta años de inestabilidad?

Gráfico 2. Burbujas especulativas y crisis en el mundo, 1970-2006

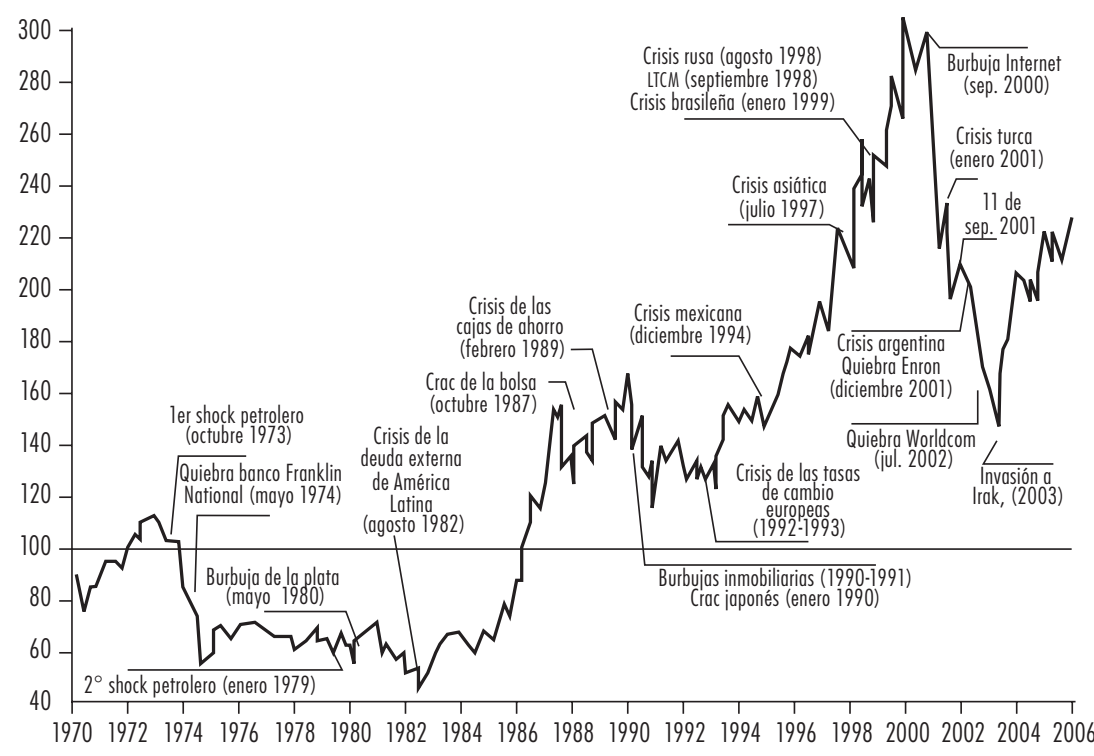

Fuente: İndice bursátil: MSCI The World Index. Se trata de un índice compuesto de acciones negociadas en 23 mercados bursátiles de países desarrollados, con un valor base de 100 al 31 de diciembre de 1969.

diferentes crisis desde los setenta hasta el 2006. Si bien ese tipo de índices no representan directamente la traumática marcha económica del mundo en esos años "evolucionan de manera contra-cíclica; muestran poco cuando el crecimiento es fuerte y se aceleran durante la depresión", señala una publicación europea, ayudan, sin embargo, a ponerla en evidencia (Le Monde, 1996: 71). Allí se destacan claramente las dieciocho burbujas y crisis más importantes de ese extenso periodo.

\section{LA CRISIS DE 2007: DE LAS PUNTOCOM A LAS SUBPRIME}

Después de la prosperidad de la segunda mitad de los años noventa, con el nuevo siglo, los problemas económicos retornaron a la potencia del norte. Aun antes del atentado a las torres gemelas comenzaron a quebrar varios fondos de inversión y empresas puntocom y de servicios con acciones sobrevaloradas en la bolsa o directamente vaciadas por sus dueños, como Enron o Worldcom. El clima especulativo permitía todo tipo de fraudes, 
comprometiendo a bancos e instituciones financieras de peso como el Citigroup. Con la amenaza del nuevo terrorismo internacional el gobierno de Bush (h) optó por una fuga hacia adelante a través de la intervención militar en Irak, acompañada por políticas internas que combinaron rebajas de impuestos para los más pudientes con un notorio incremento de los gastos gubernamentales en rubros de seguridad y defensa: por ejemplo, el gasto militar llegó a representar casi 30\% de los recursos fiscales federales. ${ }^{13}$

Mientras tanto la dicotomía entre la economía financiera y la real se profundizaba. En esta última primaba una estructura oligopólica de grandes empresas multinacionales que encontraba sus límites en una demanda declinante, pero los mercados de valores bursátiles parecían no tener techo. La espiral de burbujas especulativas generadas con productos financieros cada vez más sofisticados y riesgosos, capturaba enormes masas de capitales en busca de maximizar su rentabilidad. Sin embargo, los excedentes financieros provenían de una distribución del ingreso cada vez más regresiva a nivel mundial.

Por un lado, la modificación del gobierno empresarial, con preponderancia del accionista y la práctica de otorgar salarios altísimos (incluyendo beneficios) a sus principales ejecutivos, indujeron a las empresas a trabajar con el menor capital propio posible para aumentar el valor de sus acciones. Comparando con épocas anteriores, en 1969 el principal ejecutivo de General Motors ganaba en un ańo el equivalente de 4,3 millones de dólares actuales, mientras que un obrero de la empresa percibía unos 40.000 dólares, ambos a valores actualizados. En 2005, el ejecutivo máximo de Wal-Mart obtenía 25 millones de dólares y un empleado común de la firma 18 mil (Krugman, 2007: 138).

Por otro lado, la quiebra del compromiso establecido en los años de la posguerra entre asalariados y capitalistas, originó una fuerte presión a la baja de los salarios reales, que crecieron sustancialmente menos que la productividad favorecida por las nuevas tecnologías. La evolución del ingreso medio anual de las familias estadounidenses (con un jefe de hogar menor a los 65 años) descendió de 58.555 dólares en el año 2000 a 55.533 en el 2005, más de 3.000 dólares (a precios constantes de 2000), brecha que se compensaría con un mayor endeudamiento. ${ }^{14}$

Fenómenos de este tipo se combinaban con la apertura de nuevos mercados y la deslocalización de las empresas, creando desempleo y un exceso de mano de obra. Así se fue desencadenando una nueva crisis de superproducción. Con el propósito de paliarla y mantener la demanda, EE.UU. y otras economías avanzadas estimularon en forma desmesurada la oferta de crédito, llevando la especulación a niveles insostenibles con los productos financieros "tóxicos", que incorporaban esos créditos y se colocaban en los mercados de valores.

La crisis de las subprime que estalló en el primer semestre de 2007, resultó así la gota que rebalsó el vaso, porque no constituyó una crisis financiera más ni involucró

\footnotetext{
13 Este porcentaje resulta de dividir el gasto en defensa nacional por el total de ingresos del gobierno federal, según datos del Bureau of Economic Analysis.

14 Según el USA Census Bureau.
} 
principalmente a acciones de empresas o bonos gubernamentales. Se trató de hipotecas inmobiliarias de alto riesgo basadas en préstamos a individuos que no calificaban para los tipos de interés del mercado debido a su pobre historia crediticia. Esas hipotecas se incorporaron luego a sofisticados productos financieros vinculados directamente a la economía real a través de los propietarios insolventes de inmuebles que no podían afrontar sus compromisos financieros. Con la crisis, los bancos quisieron recuperar sus acreencias y esos deudores se quedaron sin techo, mientras los inmuebles se desvalorizaron y hundieron al sistema bancario, al mercado inmobiliario, y a la industria de la construcción y sus cadenas productivas. El sobreendeudamiento crediticio acompañó la sobreproducción de viviendas, pero también afectó a todo tipo de artículos de consumo. Algo parecido sucedió en Europa. El Gráfico 3 muestra las elevadas deudas de las familias en relación con sus ingresos en países anglosajones y en la zona del euro. ${ }^{15}$

Gráfico 3. Endeudamiento de las familias en Gran Bretaña, EE.UU. y la zona Euro. \% del ingreso disponible bruto

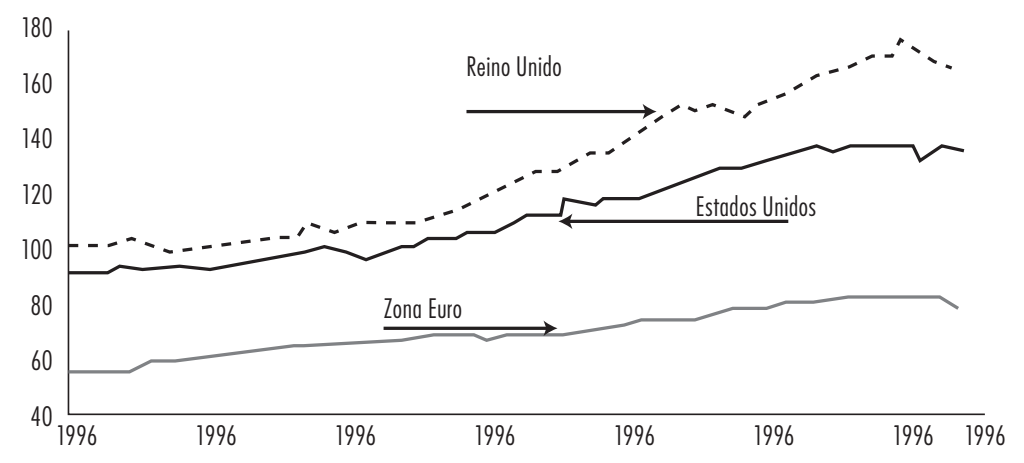

Fuente: Natixis, Alternatives Economiques.

15 La crisis iniciada en 2007 golpeó con fuerza en Europa advirtiéndose desde un primer momento, como en Estados Unidos, su involucramiento en el negocio de las subprime, que afectó tempranamente bancos de la región, como el británico Northern Rock. La crisis es más cruda en los países más débiles de la eurozona pero nadie de la región está a salvo. Los niveles de endeudamiento son también variados: van desde el $116 \%$ del PBI en 2010, como Italia, pasando por Bélgica que tiene el 99\% hasta Alemania con el 79.6\% (ver The Economist Global Debt, en Internet). Ninguno de ellos, incluso Alemania, cumple con los criterios fijados por el acuerdo de Maastricht y su ingreso a la eurozona. Se compara hoy la situación del euro con la que existía durante la vigencia de la Ley de Convertibilidad en la Argentina. La diferencia es que este país pudo devaluar y a los europeos en dificultades una acción parecida les puede costar más caro porque los obligaría a salir de una zona protegida (al menos hasta el momento). Hay quienes afirman que la cualidad de unidad de cuenta del euro tropieza con serias dificultades en distintas esferas de transacción (alimentación, automóviles e inmobiliario) como para suplantar en las prácticas cotidianas las anteriores monedas nacionales. El euro no es capaz de estabilizar el sistema de precios entre los países; depende del poder y de las políticas económicas de cada uno de ellos y de la relación entre los Estados y los agentes y grupos sociales internos. Volver a contar con una moneda propia permitiría ajustar mejor las variables internas y la relación de éstas con las internacionales. Ésta sería una solución a fin de salir del corset del euro, que podría seguir funcionando como moneda internacional al igual que el dólar. 
La crisis desplomó a la demanda agregada, lo que pronto se reflejó en diversos sectores, como en la industria automotriz donde ya se advertían desde años anteriores contracción de sus ventas y despidos masivos. El caso más emblemático fue, por su envergadura, el de la General Motors, nacionalizada por el gobierno norteamericano con participación sindical. Su situación crítica no era un simple producto de la coyuntura mundial sino también una de sus causas, ya que no se trata sólo de una crisis financiera sino que el mundo enfrenta una verdadera crisis de sobreproducción.

GM perdía dinamismo, reducía sus ventas y despidiendo masivamente a sus empleados y obreros desde varios años atrás. En 1955 participaba del 50\% en el mercado estadounidense de vehículos; en 2008 sólo del 22\%. Sin ganancias en el sector automotor desde 2001, sus pérdidas operativas en ese rubro únicamente en EE.UU. llegaron en 2008 a los 13 mil millones de dólares. Pero no sólo las tres grandes compañías automotrices norteamericanas GM, Chrysler y Ford padecían problemas similares. La venta de automóviles nuevos en los Estados Unidos cayó de 17 millones en 2006 a 13,5 millones en el 2008 y apenas rondó los 10 millones en 2009. La crisis de esta industria emblemática y el endeudamiento creciente de las familias puso en juego toda una filosofía de vida, el american way of life (Rapoport, 2009: 31).

Pero la crisis generó ante todo el derrumbe de los principales bancos de inversión, así como de numerosas entidades financieras en EE.UU. y en Europa, donde ocurrieron booms inmobiliarios similares y el sistema bancario estaba también profundamente involucrado en ese mercado y en operaciones dudosas. La masividad de los activos financieros y su rápida expansión y contracción en todo el mundo contribuyeron a difundirla y profundizarla (Eichengreen, 2008: 20).

Frente a la gravedad de la situación, el gobierno norteamericano y los de la Unión Europea decidieron intervenir directamente para salvar las principales compañías y bancos en quiebra. Así, la Reserva Federal salió al rescate de las dos entidades hipotecarias más grandes de EEUU, aunque dejó caer a Lehman Brothers - cuyo valor ascendía a más de 600 mil millones de dólares, la suma del PIB de Argentina, Bolivia, Chile, Paraguay, Uruguay, Perú y Ecuador-, produciendo otro fuerte sacudón en Wall Street. Al mismo tiempo la Fed intentó reanimar la demanda con continuas bajas en la tasa de interés. Pero todo resultó inútil. Finalmente, en octubre de 2008 el Congreso norteamericano aprobó el monto de 700 mil millones de dólares propuesto por Bush para el rescate de los bancos en quiebra, lo que fue reafirmado por el gobierno de Obama, que terminó apostando a más: 838 mil millones de dólares para estimular la economía y ayudar a los bancos.

Desde el estallido de la crisis varios centenares de bancos se declararon en quiebra en todo el país y sólo algunos contaron con la ayuda estatal. En 2009 quebraron 133 entidades, y la Corporación Federal de Seguros de Depósitos (FDIC) que protege a los depositantes -aunque hasta cierto monto, sin tener en cuenta otras acreencias y sólo para los depósitos de los bancos asegurados en ella- señalaba hacia el fin de ese año, que había cerca de 550 entidades en riesgo y que ya su balance registraba un déficit de 8.200 
millones de dólares, el primero de la institución desde 1992. Joseph Stiglitz, sostuvo a su vez que no bastaba con la ayuda y se necesitaba urgentemente crear mayores regulaciones "para restablecer la confianza en el sistema financiero" y que "no estalle una nueva crisis en pocos ańos". ${ }^{16}$

Junto al derrumbe de bancos e instituciones financieras, comprometidos en inversiones o préstamos riesgosos, otros factores también tuvieron su parte de responsabilidad en la crisis. Como, por ejemplo, la falta de reglas claras para la banca de inversión y el aprovechamiento de paraísos fiscales y mecanismos financieros para realizar maniobras especulativas o fraudulentas vinculadas muchas veces al accionar de mafias criminales.

Muchos opinan que antes de salvar a los bancos quebrados, se debería haber reestructurado la arquitectura financiera internacional, ayudado a las verdaderas víctimas -ahorristas, desocupados, asalariados que vieron disminuir sus ingresos, propietarios de inmuebles, pequeñas y medianas empresas-, y sostenido políticas productivas y creadoras de empleo. En tanto, el mundo globalizado se convirtió en un gran "corralito" del que va a ser imposible escapar con las recetas del pasado. ${ }^{17}$

\section{LOS DÉFICITS DE LA ECONOMÍA ESTADOUNIDENSE Y EL AHORRO MUNDIAL}

No sólo los norteamericanos como individuos estaban endeudados. Una de las características más salientes de la economía de Estados Unidos en las últimas décadas, fueron sus crecientes déficits fiscal y comercial. En 2008 el primero alcanzó el 3.1\% del PIB, sin incluir el paquete de rescate de 700 mil millones de dólares y las continuas inyecciones de liquidez, mientras que para el 2009 trepó a 1,5 billones de dólares, es decir la friolera del 11\% del PIB estadounidense. A su vez, su balanza de pagos registró un máximo histórico en su déficit por cuenta corriente, dentro del cual el saldo comercial constituye su principal componente negativo. En el año 2005 el mismo ascendió al 6.4\% del PIB, marca superada en el 2006 con el 6.5\%, y mantuvo parámetros similares en 2007 con el $6.1 \%$. Salvo algunos pocos años esta tendencia de constante aumento de los saldos negativos en la cuenta corriente de la balanza de pagos viene verificándose desde la década de 1970, pero se agudiza a fines de los ochenta y en todo el transcurso de los noventa.

Citado en Clarin, 13/12/09.

17 La expresión "corralito" surgió durante la crisis argentina del 2001, aludiendo a la indisponibilidad de una parte sustancial de las cuentas bancarias de individuos y empresas (cuentas corrientes y cajas de ahorro), decretada por las autoridades, para restringir la salida de depósitos, con fuertes limitaciones sobre los retiros en efectivo. La restricción sobre los plazos fijos se denominó "corralón". 
Mario Rapoport y Noemí Brenta

Gráfico 4. Estados Unidos. Saldo de la Cuenta Corriente (\% del PIB)

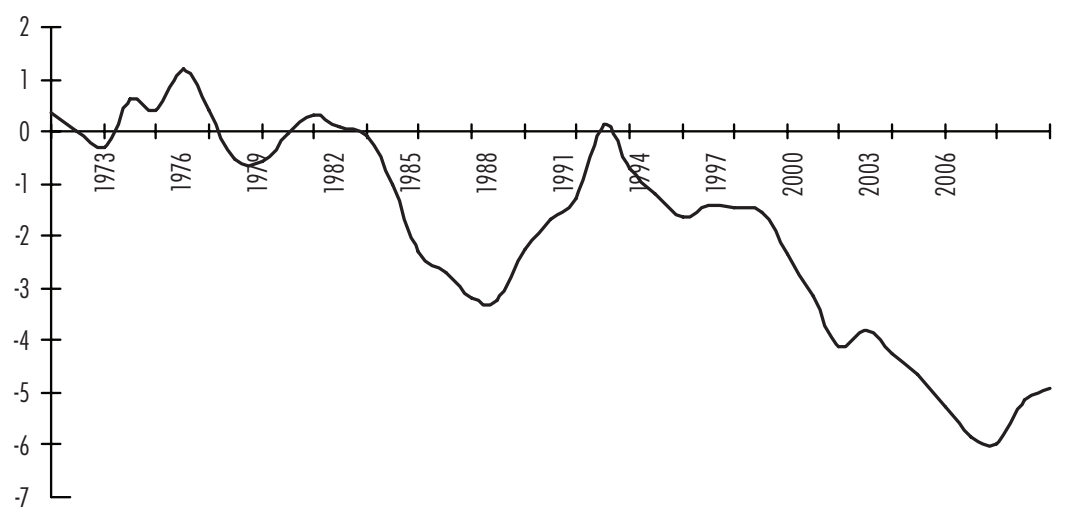

Fuente: Elaboración propia con datos del US Bureau of Economic Analysis.

El saldo en rojo para el 2008 fue de 707 mil millones de dólares, que se discrimina como muestra el cuadro siguiente.

Cuadro 2. Estados Unidos. PIB, deuda externa (2009) y componentes de la cuenta corriente del balance de pagos (2008)

\begin{tabular}{lc}
\hline Concepto & Millones de Dólares \\
\hline PIB, 2009 & 14.441 .400 \\
Deuda externa total, 31/12/09 & 13.767 .000 \\
Deuda externa/PIB, 2009 & $95 \%$ \\
Exportaciones de bienes (1) & 1.266 .900 \\
Importaciones de bienes (2) & 2.126 .400 \\
Balanza comercial (3) = (1) - (2) & -859.500 \\
Exportaciones de servicios reales (1) & 564.200 \\
Importaciones de servicios reales (2) & 412.400 \\
Balanza de servicios reales (4) = (1) - (2) & 151.800 \\
Intereses, dividendos y utilidades recibidos (1) & 809.200 \\
Intereses, dividendos y utilidades pagados (2) & 667.300 \\
Balanza de servicios financieros (5) & 141.900 \\
Balanza de transferencias e impuestos (recibidos y pagados) (6) & 141.400 \\
Saldo de Cuenta Corriente (3) + (4) + (5) + (6) & -707.200
\end{tabular}

Fuente: elaborado con datos del Bureau of Economic Analysis de los Estados Unidos. 
La economía norteamericana acumuló obligaciones externas que a fines de 2009 convertían al país en el mayor deudor planetario; con un monto equivalente a casi todo su producto bruto, a siete años de exportación de sus bienes y servicios y a algo más de la quinta parte del producto bruto mundial.

¿Cómo pudo Estados Unidos sostener ese nivel de endeudamiento? La respuesta es simple: a partir del ahorro acumulado en gran parte del globo, principalmente en los países en desarrollo. Como señala Michel Hudson desde que el gobierno estadounidense abandonó la relación del dólar con el oro, el nuevo patrón dólar le permitió obtener un doble estándar: drenar recursos de otros países sin reciprocidad, gobernando financieramente al mundo a través de su posición de deudora, no de acreedora "[...] las deudas en dólares han reemplazado al oro como respaldo de las reservas de los bancos centrales y, hasta aquí, para la oferta de crédito mundial [...] Ninguna nación antes ha sido capaz de invertir las reglas clásicas de las finanzas internacionales. [...]" EEUU ha convencido al resto del mundo "a reorientar sus economías para facilitar la evolución estadounidense de acreedora en deudora” (Hudson, 2003: 324).

De ese modo, como emisor de la divisa utilizada en las transacciones internacionales, los Estados Unidos pueden incurrir de manera persistente en déficits externos sin endeudarse en otra moneda más que en la propia, a diferencia de las demás economías del mundo. Así, el ochenta por ciento de la deuda externa norteamericana -unos 10,4 billones (trillones estadounidenses) - se encuentra denominada en dólares; sólo la décima parte en moneda de otros países. A nivel internacional, el déficit estadounidense tiene su contraparte en el ahorro externo, que es la suma de los superávits obtenidos por los países en sus intercambios con el resto del mundo. En el siguiente cuadro se aprecian los principales países deficitarios y superavitarios.

Cuadro 3. Principales déficits y superávits en cuenta corriente. Año 2008

\begin{tabular}{lccc}
\hline \multicolumn{1}{c}{ Países Deficitarios } & Miles de Millones de Dólares & Países Superavitarios & Miles de Millones de Dólares \\
\hline Estados Unidos & -706.068 & China & 426.107 \\
España & -152.655 & Alemania & 241.793 \\
Italia & -78.361 & Japón & 158.424 \\
Francia & -64.350 & Rusia & 102.401 \\
Grecia & -50.914 & Noruega & 87.886 \\
Australia & -45.624 & Países Bajos & 41.702 \\
Reino Unido & -43.260 & Suecia & 29.846 \\
Turquía & -41.937 & Austria & 13.385 \\
India & -37.231 & Suiza & 11.994 \\
Déficit total & -1.416 .394 & Superávit total & 1.140 .152 \\
\hline
\end{tabular}

Fuente: elaboración propia con datos de OCDE. 
Los recursos absorbidos por la economía norteamericana llegaron a representar en 2007 casi la mitad (el 49.2\%) del ahorro mundial. Hasta ahora el resto del mundo acepta este desbalance de los Estados Unidos porque éste es el modo de lograr la liquidez necesaria para las transacciones económicas internacionales, realizadas mayoritariamente en dólares. Pero la continua y creciente emisión de esta moneda puede provocar tarde o temprano una abrupta pérdida de confianza de su valor que licue los activos denominados en ella. De hecho, la declinación del dólar frente a las monedas de los principales países de la OCDE fue constante desde mediados de los años 1960, y se acentuó desde el 2002.

La cuestión es corregir estos desequilibrios, o al menos, llevarlos a una dimensión más manejable. Lo que ocurre es que la economía estadounidense pesa tanto en el producto mundial, que todo ajuste fiscal y/o externo del elefante repercute fuertemente en los demás países. Hasta ahora, la propuesta norteamericana consiste en sostener el déficit público hasta tanto la economía muestre signos firmes de recuperación, y en pedir a los países superavitarios, especialmente China, que revalúen sus monedas y aumenten sus importaciones. Pero es claro que se requiere algún tipo de consenso político, social e internacional para que el ajuste norteamericano se produzca, y sobre todo es necesario velar para que no se exporte a la periferia.

La experiencia más cercana en el mundo de un intento en algún aspecto similar desde el punto de vista exclusivamente monetario fue el patrón oro, aunque éste pudo funcionar en la medida en que existía un país hegemónico como Gran Bretaña, que imponía el valor de su moneda. Cuando ese poder decayó, el patrón oro se derrumbó. Ni siquiera la posterior hegemonía norteamericana en la posguerra pudo salvarlo.

El Banco Central de China señaló la necesidad de crear una nueva moneda internacional, utilizando para ello los Derechos Especiales de Giro (degs) del FMI. Lo que recuerda al Bancor, unidad monetaria propuesta por Keynes en Bretton Woods sobre la base de establecer una unión de compensaciones de los déficits y superávits del comercio internacional. Resulta quizás más realista suponer que en un futuro no muy lejano coexistan con el dólar divisas de diversas procedencias; no sólo el euro, sino también el yen, el yuan y alguna de otro país emergente. O se formen zonas monetarias en función de los procesos de integración regional (Aglietta, 2010). En todo caso Brasil y Argentina ya están tomando recaudos: pactaron basar su intercambio recíproco en sus propias monedas y no en el uso del dólar.

Keynes decía, con cierto humor, que la riqueza de Inglaterra se debía al robo de gran parte del tesoro español por el pirata Drake en 1580. Esto permitió pagar la deuda de la corona y su saldo que, puesto a una tasa de interés compuesto del 3.25\%, llegó a equivaler en 1930 al monto de las inversiones británicas en el mundo (Keynes, 1932: 362). ¿Quedará un tesoro disponible en alguna parte del globo del que los Estados Unidos u otra potencia puedan aún apropiarse como base de su dominio económico y financiero? O ese tesoro son los recursos naturales y humanos del planeta, mejor utilizados y distribuidos. 
La crisis económica mundial: ¿̇el desenlace de cuarenta años de inestabilidad?

\section{LAS TRES CRISIS Y LA HEGEMONÍA ESTADOUNIDENSE CUESTIONADA}

Las tres grandes crisis ocurridas bajo el signo de la hegemonía norteamericana -la de 1929, la de 1970 y la actual-, forman parte de un mismo proceso de largo plazo, pero cada una de ellas signa una nueva etapa del capitalismo moderno. En todas se presentan cambios tecnológicos mayores y también de las relaciones entre el capital y el trabajo, procesos especulativos ligados a los flujos irrestrictos de capitales, y caída de las tasas de ganancia en la economía real. Pero se diferencian en sus características. En 1929, la crisis se originó a partir del auge absurdo de la bolsa de valores, la sobreproducción de bienes y la inequidad distributiva de los ingresos. Una severa deflación acompañó la recesión subsiguiente, el desempleo alcanzó los niveles más altos registrados hasta ahora en el capitalismo mundial, y el PIB cayó fuertemente, sobre todo en Estados Unidos. La Segunda Guerra Mundial, con un alto costo humano y material, contribuyó a disipar finalmente sus efectos. ${ }^{18}$

Igual que en 1929, en la década de 1970 la crisis expresaba la debilidad de la moneda clave -antes, la libra; hoy, el dólar- la baja de la rentabilidad empresarial, la disminución de las tasas de crecimiento del PIB y otros desequilibrios en las economías centrales. Pero, también, el conflicto acerca de la distribución del producto mundial entre los países exportadores de materias primas y las potencias industriales. La estanflación resultó su modo de manifestarse, mientras que su resolución consistió en procurar el desmantelamiento del Estado de Bienestar construido en la posguerra, a manos de los gobiernos neoconservadores y las políticas neoliberales de los ochenta y noventa. Sus consecuencias se prolongaron hasta nuestros días, con la caída de las tasas promedio de crecimiento mundial, concentración de los ingresos y sucesivas crisis en diferentes partes del mundo. La financiarización de la economía mundial abrevó su fuente en mecanismos creados en esos años (Le Monde, 1996).

La crisis de 2007-2010 corona la inestabilidad de los últimos cuarenta años, pero, a la vez, es un resultado de ella, y por eso puede ser temible. En su origen y evolución juegan la hipertrofia de los mercados financieros y su desregulación, reflejada en las quiebras inmobiliaria y bancaria; el sobreendeudamiento y la sobreproducción de bienes; las crecientes desigualdades de ingresos y la fragilidad del sistema monetario internacional. A ello se agrega también un modelo de desarrollo productivo en el que el balance ecológico del planeta está en peligro. ¿Llevará esta crisis a una larga depresión como en la década de 1930? ¿¿Se prolongará a través de un encadenamiento de burbujas especulativas y crisis como ocurre desde los años setenta? ¿Será el principio del fin del presente modo del capitalismo o, al menos, de la hegemonía norteamericana?

Las tres crisis analizadas tienen, además, como denominador común, que se desencadenaron en los Estados Unidos, expresando desequilibrios fundamentales en las

18 En 1929 la hegemonía de la economía estadounidense, no todavía su supremacía política y militar que emergerá claramente con el conflicto bélico, está evidenciada por su propia crisis que se transforma desde sus inicios en un fenómeno mundial. El mejor relato de la misma sigue siendo el Galbraith, 1976 [1954]. 
economías del norte que, por diferentes mecanismos, se transmitieron al resto del mundo.

La primera de ellas, la de los años treinta, se produjo cuando Estados Unidos comenzaba a consolidarse como la potencia más importante del mundo capitalista y fue una resultante de la acumulación extrema de riqueza y pobreza, la celebración frenética del fin de la hoguera bélica, el desarrollo de una sociedad de consumo para unos y de ideas revolucionarias para otros, y la búsqueda de la ganancia fácil a través de la especulación financiera o del crimen organizado. El actual descalabro, que guarda en lo económico importantes similitudes con aquél, culminó un largo periodo de deterioro en la distribución de los ingresos, de drásticas políticas de desregulación de los mercados, de predominio de la esfera financiera sobre la productiva y de un excesivo endeudamiento público y privado; procesos que surgieron o se extendieron bajo la forma de una aparente resolución de la crisis de los años setenta.

La crisis actual no pone en discusión por ahora la cuestión del fin del capitalismo, aunque muestra el fracaso de las ideas neoliberales que representaron un muro invisible pero eficaz para separar a aquellos que tienen la llave de la casa del mundo de los que la miran desde afuera (la inmensa mayoría de la población del globo). De todos modos, aunque la sobrevida del sistema no esté todavía en juego se reaniman viejos debates sobre sus principales protagonistas y, en particular, sobre el presunto eclipse de la hegemonía norteamericana en el orden mundial.

¿Tocará ahora a los EE.UU. vivir una lenta decadencia como la que tuvo Gran Bretańa desde fines del siglo XIX hasta la segunda posguerra? ¿Podrá recuperarse como en el pasado gracias, en buena medida, a circunstancias excepcionales, como las guerras; la posibilidad de descargar sus crisis sobre otros países; o el repentino derrumbe de sus rivales, como pasó con la ex URSS? ¿ O debido a un salto tecnológico basado en innovaciones que aún no se vislumbran? Hace varios años que se viene discutiendo a este respecto en torno a dos cuestiones: la menor competitividad de la economía estadounidense (manifestada en los déficits gemelos y el creciente endeudamiento), y la probable disminución del poder estratégico y militar de Washington (como consecuencia de las dificultades experimentadas por las políticas intervencionistas en Irak y Afganistán). El estallido de la crisis puso estos debates en primer plano y recrudeció la polémica.

El principal argumento que esgrimen quienes sostienen que seguirá siendo la potencia hegemónica, es que ninguno de los otros países (o regiones) que podrían rivalizarlo -la Unión Europea, Japón, China o Rusia- está en condiciones políticas, militares y/o económicas de reemplazar en el corto plazo el dominio estadounidense. A nivel militar la supremacía es evidente: en el medio de la crisis, el Congreso norteamericano votó un presupuesto en el rubro para 2009 que asciende a más de 600 mil millones de dólares, equivalentes al presupuesto militar del resto de los 190 países que integran la ONU, y cerca del $50 \%$ del presupuesto militar mundial. ${ }^{19}$

19 Base de datos del Stockholm Internacional Peace Research Institute; y Center for Defense Information, U.S. Military Spending, 1945-2008. 
También se afirma que la crisis de los años setenta benefició a Estados Unidos porque lo ayudó a recuperar en lo económico su iniciativa monetaria mientras que, en lo militar, se retiraba de Vietnam y recomponía sus relaciones con China. Episodios que fueron interpretados como el comienzo de la decadencia norteamericana -como las crisis financiera y energética- a la luz de los acontecimientos posteriores no lo fueron. En cambio, comenzó entonces la "gran transformación" geopolítica del sistema mundial, que aún continúa, asumiendo EE.UU. y China la constitución de un nuevo eje dinámico de la economía internacional. De este modo, el proyecto imperial norteamericano fue renovado a plena conciencia, o impulsado por circunstancias críticas, según como se lo interprete, en el mismo momento en que, para muchos, se iniciaba la declinación de su hegemonía. ${ }^{20}$

La segunda línea de pensamiento, la de la declinación de Estados Unidos, tiene también sus partidarios, sobre todo después de los atentados del 11 de septiembre y de la invasión a Irak donde los límites del poder militar estadounidense se hicieron más transparentes. Si a esto se le agrega la crisis financiera, la idea de un "siglo XXI norteamericano global", que estaba detrás del Consenso de Washington y la caída del Muro de Berlín, parece ya desvanecerse. Comenzaron a advertirse más claramente los desajustes de la economía estadounidense, que incluyen la caída del mismo dólar, y también el fracaso del intervencionismo militar de carácter presuntamente "preventivo".

La declinación se avizora, de todas formas, en el largo plazo, y lo más probable es que se produzca un nuevo "reparto" imperial, cuyos comienzos podrían ya observarse desde la llegada de Obama al gobierno - más débil en sus inicios que su predecesor cuando fue elegido-, en el cual Washington sigue siendo protagonista pero dejando el juego más abierto a otros actores como la Unión Europea y los gigantes asiáticos. Quienes analizan el alto grado de vinculación a nivel de las empresas trasnacionales y de los gobiernos de los países desarrollados en un sistema mundializado son proclives a prever una salida "consensuada" de la crisis, con predominio de EE.UU. pero también con una mayor participación de otras potencias. Otros anticipan una cruda competencia por los espacios de poder económico y político y recuerdan que la crisis de 1930 se saldó con una guerra mundial. ${ }^{21}$

La conclusión principal que surge de ese panorama geopolítico y económico no pareciera ser, sin embargo, la definitiva decadencia del gigante americano, sino un mundo más multipolar aunque lleno de incertidumbres. La UE, sufre la recesión, carece de un gobierno central y su peso estratégico y militar es escaso. Además, la profundización de la crisis en algunos países de la eurozona pone en peligro la estabilidad del euro, por ahora la principal divisa rival del dólar.

20 En el origen de la tesis de la vigente hegemonía norteamericana se hallan los trabajos de Strange, 2002. Para una defensa actual de la misma ver Fiori, Medeiros y Serrano, 2008.

21 Entre los que acuerdan con la tesis de la decadencia del país del norte ver Wallerstein, 2006 y Ramonet, 2009; Kennedy, 1994, es un libro pionero en este sentido escrito en los ańos ochenta. 
En el continente asiático, la gran incógnita es el futuro de China, que aunque proclama abiertamente su intención de terminar con el predominio del dólar aún sigue financiando la economía norteamericana. También tiene que resolver el problema de la integración de su mercado nacional, dividido en un minoritario sector avanzado y otro que incluye a la gran mayoría de su población, lo que supone no sólo un problema económico sino también de control político. Japón, Corea del Sur, la India, constituyen otros vértices importantes de la ecuación continental asiática.

En este marco, asoman bloques políticos y económicos, como el del sur del continente latinoamericano, integrado por países que después de padecer el fracaso de políticas de ajuste y endeudamiento muestran en su mayoría un dinamismo económico sorprendente y parecen escapar de la crisis. En la periferia de la economía mundial, sobre todo en Asia y América Latina, surgen adicionales protagonistas que buscan un nuevo lugar en el mundo.

Las crisis del capitalismo han significado siempre cambios económicos y políticos traumáticos. Sin duda, ya nada será igual que antes. Pero es necesario aprender de lo ocurrido de modo de convertir el planeta en que vivimos en un sitio más habitable y justo, con un mejor uso de sus recursos y un reparto más equitativo de los ingresos del conjunto de la sociedad.

\section{BIBLIOGRAFÍA}

Aglietta, Michel, "Le dollar, le yuan et le système monétaire international”, en L'economie politique, N 45, París, enero 2010.

Bellamy Foster, John y Magdoff, Fred, The Great Financial Crisis: Causes and Consequences, Nueva York, Monthly Review Press, 2009.

Bourguinat, Henri, La tirannie des marches, París, Economica, 1995.

Boyer, Robert, La teoría de la regulación: un análisis crítico, Buenos Aires, Humanitas, 1989.

Brenta, Noemí, Argentina atrapada. Historia de las relaciones con el FMI, 1956-2006, Buenos Aires, Ediciones Cooperativas, 2008.

C.E.P.I.I., Economie mondiale, la montée des tensione, Economica, París, 1983. Eatwell, John y Taylor, Lance, "Finanzas globales en riesgo. Un análisis a favor de la regulación internacional”, Buenos Aires, Cefidar-Siglo XXI, 2005.

Eichengreen, Barry, "Dix questions à propos de la crise des prêts subprime" en Révue de la stabilité financiare, $\mathrm{N}^{\circ} 11$, febrero 2008.

Figallo, Beatriz y García de Ceretto, Josefa, "Historia y complejidad. La historia del tiempo presente”, en Res Gesta, núm. 41, Rosario, Instituto de Historia, UCA, 2003, pp. 9-40.

Fiori, José Luis; Medeiros, Carlos y Serrano, Franklin, O Mito do Colapso do Poder Americano, Río de Janeiro, Record, 2008. 
Friedman, Milton, "The role of monetary Policy", American Economic Review, marzo 1968.

Galbraith, John K., El crac del 29, Barcelona, Ariel, 1976 (1954).

Greenspan, Alan, La era de las turbulencias, Buenos Aires, Ed. B, 2008.

Hilferding, Rudolf, El capital financiero, Madrid, Tecnos, 1963 (1910).

Hudson, Michael, Superimperialism. The Economic Strategy of American Empire, Londres, Pluto Press, 2003.

Kennedy, Paul, Auge y caída de las grandes potencias, Barcelona, P\&G, 1994

Keynes, John M., Essays in Persuasion, Vol. Ix, Nueva York, Harcourt Brace, 1932.

Kindleberger, Charles P., Manias, pánicos y cracs. Historia de las crisis financieras, Barcelona, Ariel, 1991 (1989).

Krugman, Paul, De vuelta a la economía de la Gran Depresión y la Crisis del 2008, Buenos Aires, Norma, 2009.

Krugman, Paul, The Conscience of a Liberal, Nueva York, Norton, 2007.

La Documentation Française, Problèmes économiques, № 2637, París, 27/10/99.

Le Monde, Croissance et crises, 1944-1996. Cinquante ans d'histoire économique, Numero Special des Dossiers et Documents, Paris, octubre, 1996.

Marichal, Carlos, Nueva historia de las Grandes Crisis Financieras. Una perspectiva global, 1873-2008, Buenos Aires, Debate, 2010.

Markowitz, Harry, Portfolio Selection, Efficient Diversification of Investments, Nueva York, Wiley and Sons, 1959.

Marx, Karl, El capital, tomo III, México, Siglo XXI, 2006 [1897].

Minsky, Hyman, Stabilizing an unstable economy, Nueva York, McGraw-Hill, 2008 (1986).

Ramonet Ignacio, La catástrofe perfecta. Crisis del siglo y refundación del porvenir, Buenos Aires, Capital Intelectual, 2009.

Rapoport, Mario, Tiempos de crisis, vientos de cambio. Argentina y el poder global, Buenos Aires, Norma, 2002.

Rapoport, Mario, "El derrumbe de un símbolo. La nacionalización de General Motors cuestiona un estilo de vida", en Le Monde Diplomatique, № 122, Buenos Aires, agosto 2009, p. 31.

Smith, Adam, Investigación sobre la naturaleza y causa de la riqueza de las naciones, México, Fondo de Cultura Económica, 2004 (1776).

Strange, Susan, "The Persistent Myth of Lost Hegemony", en R. Tooze y C. May, Authority and Markets. Susan Strange's Writings on International Political Economy, Londres, Palgrave-Macmillan, 2002.

Stiglitz, Joseph, Caida Libre, Buenos Aires, Taurus, 2010.

Varesi, Gastón Ángel, "La Argentina Posconvertibilidad: modelo de acumulación", en

Problemas del Desarrollo, vol. 41, núm. 161, México, IIEc-UnAM, abril-junio de 2010, pp. 141-164. 
Mario Rapoport y Noemí Brenta

Wallerstein, Immanuel, La decadencia del poder estadounidense, Buenos Aires, Capital Intelectual, 2006. 